\title{
The Relationship Between Causative Microorganisms and Airway Obstruction in Patients with COPD Exacerbation
}

\author{
(D) Mehmet Erdem Çakmak
}

Türkiye Yüksek ihtisas Training and Research Hospital, Department of Critical Care, Ankara, Turkey

\section{Abstract}

Objective: Chronic obstructive pulmonary disease (COPD) is a common, preventable and treatable disease. Exacerbations and comorbidities contribute to the severity of the disease. In our study, we aimed to evaluate the relationship between causative microorganisms and airway obstruction in patients hospitalized for COPD exacerbation.

Methods: Sputum and blood cultures of 75 patients, who were admitted to Nevşehir State Hospital Chest Diseases Unit between January 2015 and January 2016 and who were diagnosed as COPD exacerbation, were analyzed retrospectively. The relationship between microorganisms in sputum culture and airway obstruction was evaluated. Forced expiratory volume in one second $\left(\mathrm{FEV}_{1}\right)$ value was used to evaluate airway obstruction.

Results: Of the 75 patients evaluated in our study, 45 (60\%) were male and 30 (40\%) were female. The mean age was 61.2 years. Isolated microorganisms were as follows: H. influenzae in 12 (16\%) patients, S. pneumoniae in nine (\%12) patients, M. catarrhalis in six (8\%) patients, P. aeruginosa in four (5.3\%) patients, E. coli in three (4\%) patients, K. pneumoniae in three (4\%) patients, and methicillin-sensitive S. aureus in one (1.3\%) patient. No statistically significant difference was found between the microorganisms in terms of airway obstruction $(p>0.05)$.

Conclusion: We did not find a correlation between the causative microorganism and airway obstruction in patients hospitalized for COPD exacerbation. Keywords: COPD exacerbation, sputum culture, airway obstruction, FEV 1

\section{INTRODUCTION}

Chronic obstructive pulmonary disease (COPD) is a preventable and treatable disease characterized by the chronic inflammatory response of the airways and lungs against harmful gases and particles, leading to a progressive limitation of airflow. Exacerbations and comorbidities that occur during the course of the disease cause an increase in the severity of the disease (1).

Exacerbation of COPD has been described as a condition characterized by acute deterioration of the patient's respiratory tract symptoms leading to drug change (1). There is a loss of pulmonary functions due to exacerbations, which leads to impaired quality of life and an increase in morbidity and mortality.
The etiology of COPD exacerbations consists of tracheobronchial infections (50-70\%) and air pollution (10\%), and the etiology cannot be detected in about $30 \%$ of exacerbations. In patients with COPD, exacerbations should be prevented and treated in order to prevent disease progression and to maintain quality of life.

In our study, we aimed to evaluate tracheobronchial infectious agents in sputum culture, and the relationship between cautious microorganisms and airway obstruction in patients hospitalized for COPD exacerbation.

\section{METHODS}

Seventy-five patients, who were admitted to Nevşehir State Hospital Chest Diseases Unit with COPD exacerbation between January 2015 and January 2016, were evaluated retrospectively.

E-posta: erdem.cakmak@deu.edu.tr ORCID ID: orcid.org/0000-0001-7899-3004

Cite this article as: Çakmak ME. The Relationship Between Causative Microorganisms and Airway Obstruction in Patients with COPD Exacerbation. Eur Arch Med Res 2019; 35 (2): 88-91

๑Copyright 2019 by the Health Sciences University, Okmeydanı Training and Research Hospital European Archives of Medical Research published by Galenos Publishing House. 
Patients who were not treated with antibiotics one month before admission were evaluated. Patients with cystic fibrosis, asthma and bronchiectasis were excluded from the study.

Sputum and blood cultures that were obtained for the isolation of microbiological agent causing acute exacerbation of COPD were examined. Sputum samples with polymorphonuclear leukocyte count $>25$ and mouth epithelial cells $<10$ in all areas were evaluated. Pulmonary function tests performed in the stable period of three months before the acute exacerbation were evaluated. Forced expiratory volume in 1 second $\left(\mathrm{FEV}_{1}\right)$ value was used to evaluate airway obstruction. Patients with positive sputum culture were divided into two groups according to $\mathrm{FEV}_{1}\left(\mathrm{FEV}_{1}>50 \%\right.$ and $\left.\mathrm{FEV}_{1}<50 \%\right)$.

\section{Statistical Analysis}

Statistical analyzes were performed using IBM SPSS Statistics 22 software. Mean and standard deviation was used for numerical data when evaluating the study data. Frequency distributions were calculated for comorbidities and isolated microorganisms from sputum cultures. The chi-square test was used to evaluate the relationship between $\mathrm{FEV}_{1}$ value and the causative microorganism.

\section{RESULTS}

Of the 105 patients evaluated in our study, 30 patients were not included in the study because of antibiotic use up to one month before hospitalization and having comorbidities such as asthma and bronchiectasis. Of the 75 patients evaluated in our study, $45(60 \%)$ were male and $30(40 \%)$ were female. In our study, the mean age of patients was 61.2 \pm 16.3 (range, 40-85).

The complaints of the patients were as follows: increased dyspnea in 65 (86\%) patients, cough in 60 (80\%) patients, increased sputum in $55(73 \%)$ patients, and change in sputum color in $36(48 \%)$ patients. While $50(66 \%)$ patients continued smoking, 25 (33\%) had quitted smoking.

The mean $\mathrm{FEV}_{1}$ was $1.35 \pm 0.75 \mathrm{~L}(47.7 \% \pm 20.68), \mathrm{FEV}_{1} /$ forced vital capacity (FVC) was $50.4 \% \pm 15.2$, and FVC was $1.79 \pm 0.79 \mathrm{~L}$ (56.81 \pm 17.45$)$.

Twenty-eight (37\%) of the 75 patients had hypertension, 24 (32\%) had diabetes mellitus, 18 (24\%) had congestive heart failure, 12 (16\%) had atherosclerotic heart disease, four (5\%) had lung cancer, four (5\%) had obstructive sleep apnea and three (4\%) had depression (Table 1).

Isolated microorganisms were as follows: H. influenzae in 12 (16\%) patients, S. pneumoniae in nine (\%12) patients, M. catarrhalis in six (8\%) patients, P. aeruginosae in four (5.3\%) patients, E. coli in three (4\%) patients, K. pneumoniae in three (4\%) patients, and methicillin-sensitive S. aureus in one (1.3\%) patient. Normal throat flora elements were observed in 37 (49.3\%) patients (Table 2).

Positivity was detected in only four of the blood cultures obtained during hospitalization of the patients. Isolated microorganisms were S. pneumoniae in one (1.3\%) patient, E. coli in one (1.3\%) patient, $H$. influenzae in one (1.3\%) patient and K. pneumonia in one (1.3\%) patient.

$\mathrm{FEV}_{1}$ was $>50 \%$ in $18(47 \%)$ patients and $<50 \%$ in 20 (53\%) patients with positive sputum culture (Table 3).

As they are the most common isolated microorganisms in acute bacterial COPD exacerbations, S. pneumoniae, $H$. influenzae and $M$. catarrhalis growth in patients with $\mathrm{FEV}_{1}>50 \%$ were compared with the group with $\mathrm{FEV}_{1}<50 \%$ (group with severe airway obstruction). There was no statistically significant difference between the two groups in terms of sample distribution $(p>0.05)$.

Patients with $\mathrm{FEV}_{1}>50 \%$ and $<50 \%$ were compared in terms of gram (+) and gram (-) bacteria growth. There was no statistically significant difference between the two groups in terms of gram $(+)$ and gram (-) bacteria growth $(p>0.05)$.

\begin{tabular}{|l|l|l|}
\hline Table 1. Comorbidities of the study cohort & Number & $\%$ \\
\hline Comorbidity & 28 & 37 \\
\hline Hypertension & 24 & 32 \\
\hline Diabetes mellitus & 18 & 24 \\
\hline Congestive heart failure & 12 & 16 \\
\hline Atherosclerotic heart disease & 4 & 5 \\
\hline Lung cancer & 4 & 5 \\
\hline Obstructive sleep apnea & 3 & 4 \\
\hline Depression & & \\
\hline
\end{tabular}

\begin{tabular}{|l|l|l|}
\hline \multicolumn{3}{|c|}{ Table 2. Distribution of bacteria isolated in sputum culture } \\
\hline Bacteria & Number & $\%$ \\
\hline H. influenzae & 12 & 16 \\
\hline S. pneumoniae & 9 & 12 \\
\hline M. catarrhalis & 6 & 8 \\
\hline P. aeruginosae & 4 & 5.3 \\
\hline E. coli & 3 & 4 \\
\hline K. pneumoniae & 3 & 4 \\
\hline S. aureus (methicillin-sensitive) & 1 & 1.3 \\
\hline Normal throat flora elements & 37 & 49.3 \\
\hline Total & 75 & 100 \\
\hline
\end{tabular}




\section{DISCUSSION}

Exacerbation of COPD is characterized by acute deterioration of the patient's respiratory tract symptoms leading to drug change (1). Exacerbations have negative effects on morbidity and mortality. As the disease progresses, the frequency and severity of exacerbations increase and the quality of life of COPD patients is further reduced.

The etiology of COPD exacerbations consists of tracheobronchial infections (bacterial agents 40-50\%, viral agents 30-40\%, atypical bacterial agents 5-10\%) and air pollution (10\%), and the etiology cannot be detected in about 30\% of exacerbations (2). Respiratory pathogens can be detected in the respiratory tract in the stable period of the disease, so the role of infectious agents in exacerbations is controversial. In bronchoscopic studies, it was observed that approximately half of the patients had higher concentrations of bacteria in the lower respiratory tract during exacerbation than the stable period of the disease (3). In our study, we detected $50.7 \%$ bacterial infection in the etiology of exacerbations.

In a study to determine the indication for antibiotics in COPD exacerbations, the basic criterion for antibiotic indication was found to be sputum purulence. In this study, 86 patients with positive sputum culture were evaluated and 73 of them had purulent sputum (sensitivity $84-94 \%$, specificity $77-84 \%$ ) (4). In our study, sputum purulence was increased in 36 (48\%) patients. According to the Committee on Publication Ethics study, it is recommended that antibiotics should be given in case of visualization of bacteria with gram staining, decrease in respiratory function, and two or more exacerbation history within last year, and antibiotic treatment is not recommended in the absence of any of these criteria (absence of all these criteria has $100 \%$ negative predictive value) (5).

\begin{tabular}{|c|c|c|c|c|}
\hline $\begin{array}{l}\text { Causative } \\
\text { microorganism }\end{array}$ & $\begin{array}{l}\mathrm{FEV}_{1} \\
>50 \%\end{array}$ & $\begin{array}{l}\mathrm{FEV}_{1} \\
<50 \%\end{array}$ & Total & p \\
\hline H. influenzae & $5(42 \%)$ & $7(58 \%)$ & 12 & 0.148 \\
\hline S. pneumoniae & $5(55.5 \%)$ & $4(44.5 \%)$ & 9 & 0.164 \\
\hline M. catarrhalis & $3(50 \%)$ & $3(50 \%)$ & 6 & 0.213 \\
\hline E. coli & $1(33.3 \%)$ & $2(66.6 \%)$ & 3 & 0.394 \\
\hline K. pneumoniae & $1(33.3 \%)$ & $2(66.6 \%)$ & 3 & 0.394 \\
\hline P. aeruginosae & $2(50 \%)$ & $2(50 \%)$ & 4 & 0.369 \\
\hline $\begin{array}{l}\text { S. aureus } \\
\text { (methicillin-sensitive) }\end{array}$ & $1(100 \%)$ & - & 1 & 0.512 \\
\hline Total & $18(47 \%)$ & $20(53 \%)$ & 38 & 0.102 \\
\hline
\end{tabular}

The most frequently causative bacterial agents responsible for exacerbations are $H$. influenzae, S. pneumoniae and M. catarrhalis. Enteric gram (-) bacteria and P. aeruginosa are increasingly isolated in patients with severe airway obstruction, hypoxemia, malnutrition, comorbidity, frequent hospitalization and antibiotic use $(6,7,8)$. In our study, similar to literature, the most frequently isolated infectious agents were $H$. influenzae in $12(16 \%)$ patients, S. pneumoniae in nine (12\%) patients and $M$. catarrhalis in six (8\%) patients. In recent years, studies that are supported by serological diagnostic methods reported that Chlamydia pneumoniae and Mycoplasma pneumoniae might be responsible for a significant proportion of COPD exacerbations (4-34\%), and atypical bacteria were not detected in studies using polymerase chain reaction (9).

Viruses are responsible for $15-40 \%$ of COPD exacerbations caused by infectious causes and a significant proportion of these infections are found together with bacterial infections $(10,11)$. In a study by Seemungal et al., (12) they stated that $64 \%$ of patients with COPD exacerbations had common cold 18 days before exacerbation and that rhinoviruses were the most common respiratory tract virus with a rate of 58\%. In our study, no growth was detected in sputum culture of 37 (49.3\%) patients and we think that atypical bacteria, viruses or non-infectious causes may cause exacerbation in these patients.

Eller et al. (13) reported that the microorganisms isolated in the exacerbations of infective COPD might change with the degree of impairment of pulmonary function. They reported that most of the microorganisms isolated in patients with $\mathrm{FEV}_{1}$ values $>50 \%$ were $S$. pneumoniae, $H$. influenzae and $M$. catarrhalis, and that gram-negative microorganisms such as Enterobacteriaceae and Pseudomonas spp. were more common in cases with severe airway obstruction with a $\mathrm{FEV}_{1}<35 \%$. Miravitlles et al., (14) found higher rates of Pseudomonas spp. and $H$. influenza in patients with COPD exacerbation and FEV $<50 \%$. In our study, we found no significant difference in the distribution of causative microorganisms in cases with severe airway obstruction $\left(\mathrm{FEV}_{1}<50 \%\right)$ and $\mathrm{FEV}_{1}>50 \%$. We believe that the retrospective nature of our study and the low number of causative microorganisms in the sputum culture may be effective on this result.

\section{CONCLUSION}

We aimed to evaluate the relationship between tracheobronchial infectious agents and airway obstruction in patients with COPD exacerbation. We did not find a relationship between the 
distribution of cautious microorganisms and airway obstruction in COPD exacerbations. We believe that this is due to the low number of patients with isolated causative agents.

\section{Ethics}

Ethics Committee Approval: Retrospective study.

Informed Consent: Retrospective study.

Peer-review: Externally peer-reviewed.

Conflict of Interest: No conflict of interest was declared by the authors.

Financial Disclosure: The authors declared that this study received no financial support.

\section{REFERENCES}

1. Global Initiative for Chronic Obstructive Lung Disease (GOLD). Global strategy for the diagnosis, management, and prevention of chronic obstructive pulmonary disease: updated 2014. http://www.goldcopd.org/uploads/users/ files/GOLD_Report2014_Feb07.pdf

2. Sapey E, Stockley RA. COPD exacerbations 2: Aetiology. Thorax 2006;61:250-

3. Sethi S. Bacteria in exacerbations of chronic obstructive pulmonary disease Phenomenon or Epiphenomenon? Proc Am Thorac Soc 2004;1:109-14.

4. Stockley RA, O'Brien C, Pye A, Hill SL. Relationship of sputum color to nature and outpatient management of acute exacerbations of COPD. Chest 2000;117:1638-45.
5. Van der Valk P, Monninkhof E, van der Palen J, Zielhuis G, van Herwaarden C, Hendrix R. Clinical predictors of bacterial involvement in exacerbations of chronic obstructive pulmonary disease. Clin Infect Dis 2004;39:980-6.

6. Sayıner A, Polatı M, Çöplü L. Türk Toraks Derneği Akut Bronșit ve KOAH ve Bronșektazi Alevlenmelerinde Antibiyotik Tedavisi Uzlaşı Raporu. Turk Toraks Derg 2009;10:3-7.

7. Eller J, Ede A, Schaberg T, Niederman MS, Mauch H, Lode H. Infective exacerbations of chronic bronchitis: relation between bacteriologic etiology and lung function. Chest 1998;113:1542-8.

8. Incalzi RA, Corsonella A, Pedone J, Masotti G, Rengo F, Grassi V, et al. Use of antibiotics in elderly patients with exacerbated COPD: The OLD-Chronic Obstructive Pulmonary Disease Study. J Am Geriatr Soc 2006;54:642-7.

9. Diederen BMW, van der Valk PDLPM, Kluytmans JAWJ, Peeters MF, Hendrix R. The role of atypical respiratory pathogens in exacerbations of chronic obstructive pulmonary disease. Eur Respir J 2007;30:240-4.

10. Wedzicha JA. Role of viruses in exacerbations of chronic obstructive pulmonary disease. Proc Am Thorac Soc 2004;1:115-20.

11. Rohde G, Wiethege A, Borg I, Kauth M, Bauer TT, Gillissen A, et al. Respiratory viruses in exacerbations of chronic obstructive pulmonary disease requiring hospitalization: a case-controlled study. Thorax 2003;58:37-42.

12. Seemungal T, Harper-Owen R, Bhowmik A, Moric I, Sanderson G, Message $S$, et al. Respiratory viruses, symptoms, and inflammatory markers in acute exacerbations and stable chronic obstructive pulmonary disease. Am J Respir Crit Care Med 2001;164:1618-23.

13. Eller J, Ede A, Schaberg T, Niederman MS, Mauch H, Lode H. Infective exacerbations of chronic bronchitis: relation between bacteriologic etiology and lung function. Chest 1998;113:1542-8.

14. Miravitlles M, Espinosa C, Fernández-Laso E, Martos JA, Maldonado JA, Gallego $M$. Relationship between bacterial flora in sputum and functional impairment in patients with acute exacerbations of COPD. Chest 1999;116:40-6. 